\title{
Spatial Distributions of Alloying Elements Obtained from Atom Probe Tomography of the Amorphous Ribbon $\mathrm{Fe}_{75} \mathrm{C}_{11} \mathrm{Si}_{2} \mathrm{~B}_{8} \mathrm{Cr}_{4}$
}

\author{
Jinkyung Shin, Seonghoon Yi ${ }^{\dagger}$, Konda Gokuldoss Pradeep*, \\ Pyuck-Pa Choi* and Dierk Raabe*
}

\author{
Dept. of Materials Science and Metallurgical Engineering, Kyungpook National University, Daegu 702-701, Korea \\ *Dept. of Microstructure Physics and Alloy Design, Max-Planck Institute for Iron Research GmbH, \\ 40237 Duesseldorf, Germany
}

(Received December 17, 2012 : Received in revised form January 24, 2013 : Accepted January 28, 2013)

\begin{abstract}
Spatial distributions of alloying elements of an Fe-based amorphous ribbon with a nominal composition of $\mathrm{Fe}_{75} \mathrm{C}_{11} \mathrm{Si}_{2} \mathrm{~B}_{8} \mathrm{Cr}_{4}$ were analyzed through the atom probe tomography method. The amorphous ribbon was prepared through the melt spinning method. The macroscopic amorphous natures were confirmed using an X-ray diffractometer (XRD) and a differential scanning calorimeter (DSC). Atom Probe (Cameca LEAP 3000X HR) analyses were carried out in pulsed voltage mode at a specimen base temperature of about $60 \mathrm{~K}$, a pulse to base voltage ratio of $15 \%$, and a pulse frequency of $200 \mathrm{kHz}$. The target detection rate was set to 5 ions per 1000 pulses. Based on a statistical analyses of the data obtained from the volume of $59 \times 59 \times 33 \mathrm{~nm}^{3}$, homogeneous distributions of alloying elements in nano-scales were concluded. Even with high carbon and strong carbide forming element contents, nano-scale segregation zones of alloying elements were not detected within the Fe-based amorphous ribbon. However, the existence of small sub-nanometer scale clusters due to short range ordering cannot be completely excluded.
\end{abstract}

Key words amorphous alloy, atom probe tomography, melt-spinning process, alloy design, carbide former.

\section{Introduction}

Amorphous alloys have many beneficial properties that cannot be obtained in crystalline alloys. These properties are attributed to unique atomic structures of amorphous alloys. That is, amorphous alloys have short range ordered atomic structures and thus, tend to form a single phase with relatively large amounts of free volume and with extremely supersaturated alloying elements. In general, amorphous alloys are known to be chemically/structurally homogeneous. ${ }^{1,2)}$ However, detailed studies on the atomic arrangements of specific amorphous alloys reveal nano-scale segregation zones of specific elements significantly affecting macroscopic properties of amorphous alloys. ${ }^{3-6)}$ Therefore, information on the spatial distribution of supersaturated alloying elements is important to understand macroscopic properties of the amorphous alloy. The chemical heterogeneity of amorphous alloys can be effectively studied in an atomic scale using an atom probe facility. ${ }^{7-9)}$ That is, due to the recent development in Atom Probe Tomography(ATP) technology, large amounts of data can be statistically processed in a short period. Based upon results of the statistical treatments of data, spatial distributions of alloying elements within the amorphous alloy can be reasonably inferred. In this study, spatial distributions of alloying elements in a Fe-based amorphous ribbon $\left(\mathrm{Fe}_{75^{-}}\right.$ $\mathrm{C}_{11} \mathrm{Si}_{2} \mathrm{~B}_{8} \mathrm{Cr}_{4}$ ) have been studied using an atom probe facility. The Fe-based amorphous alloys with high carbon contents can be fabricated using high carbon cast irons and thus, have economical and environmental benefits for practical applications of the Fe-based amorphous alloys. ${ }^{10)}$ Since strong carbide forming elements $(\mathrm{Cr}, \mathrm{Si}, \mathrm{B})$ have been added to the high carbon $\mathrm{Fe}$ based amorphous alloy to enhance glass forming ability as well as corrosion resistance, the spatial distributions of these elements within the high carbon Fe based amorphous alloy will be an important information to understand macroscopic properties as well as phase transformations during post-materials

\footnotetext{
${ }^{\dagger}$ Corresponding author

E-Mail : yish@knu.ac.kr (S. Yi, Kyungpook Nat'l Univ.)
}

(C) Materials Research Society of Korea, All rights reserved.

This is an Open-Access article distributed under the terms of the Creative Commons Attribution Non-Commercial License (http://creativecommons.org/licenses/by-nc/3.0) which permits unrestricted non-commercial use, distribution, and reproduction in any medium, provided the original work is properly cited. 
processing of the Fe-based amorphous ribbon.

\section{Experimental Procedure}

2.1 Preparation and metallographic analysis of the Fe-based amorphous ribbon

Ingots around $15 \mathrm{~g}$ with the nominal composition of $\mathrm{Fe}_{75} \mathrm{C}_{11} \mathrm{Si}_{2} \mathrm{~B}_{8} \mathrm{Cr}_{4}$ (atomic \%) was arc-melted using a nonconsumable electrode arc melting facility under an $\mathrm{Ar}$ atmosphere. High purity elements with purities higher than $99.9 \mathrm{wt} \%$ were weighed to form a mixture of pure elements and then, the mixture was arc-melted more than 3 times to secure chemical homogeneity. Pieces of the arc melted ingot were remelted in a quartz tube and ejected onto a copper wheel rotating at the linear speed of $35 \mathrm{~m} / \mathrm{s}$. From the melt spinning process, an amorphous ribbon with the dimension of(W $2 \mathrm{~mm} \times \mathrm{t} 25 \mu \mathrm{m})$ was prepared. X-ray diffraction(XRD) measurements of the ribbon were carried out using $\mathrm{Cu} \mathrm{K} \alpha$ radiation with the scanning rate of $4 \%$ $\mathrm{min}$. The ribbon was continuously heated at the heating rate of $40 \mathrm{~K} / \mathrm{min}$ in a differential thermal calorimetrer (DSC) to measure thermal properties of the ribbon.

\subsection{Atom probe analysis for the Fe-based amorph- ous ribbon}

Atom Probe(Cameca LEAP 3000X HR) analyses were carried out in pulsed voltage mode at a specimen base temperature of about $60 \mathrm{~K}$, a pulse to base voltage ratio of $15 \%$ and a pulse frequency of $200 \mathrm{kHz}$. The target detection rate was set to 5 ions per 1000 pulses. Fig. 1 illustrates the principles of APT taken from Ref. ${ }^{11)}$ For an APT analysis a sharp needle-shaped sample having a typical radius of curvature of $100 \mathrm{~nm}$ or below, is prepared. By applying a high positive base voltage to the specimen and superposing either ultra-fast voltage or laser pulses to the base voltage, controlled field-evaporation of ions from

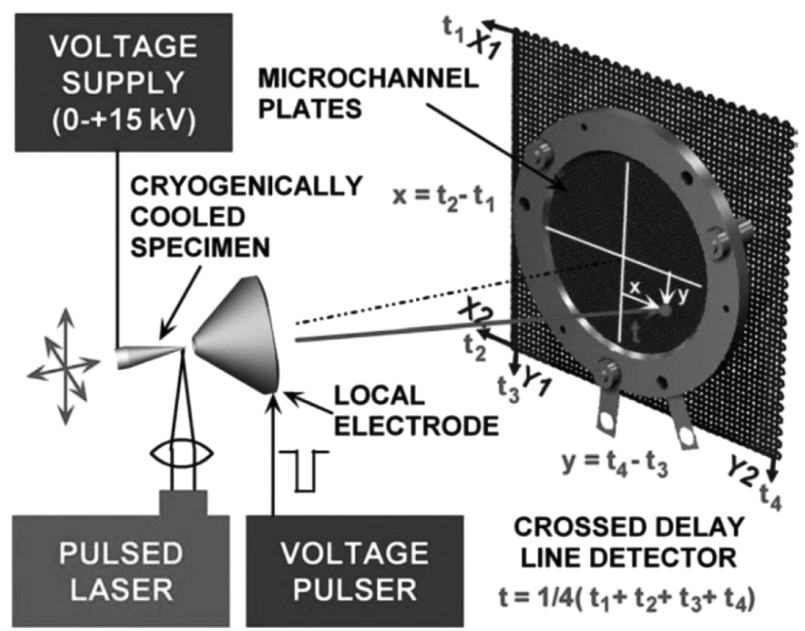

Fig. 1. Schematic of APT taken from Ref. ${ }^{1)}$
Table 1. Conditions for the atom probe analysis.

\begin{tabular}{cc} 
Pulse rate & $200 \mathrm{kHz}$ \\
Pulse Fraction & $15 \%$ \\
Target Evap & $0.5 \%$ \\
Temperature & $60 \mathrm{~K}$ \\
\hline
\end{tabular}

the specimen surface is induced. The field-evaporated ions are accelerated by the electric field towards a position sensitive detector that records their time-of -flight and impact positions. The mass-to-charge ratio is determined from the potential energy $\mathrm{neV}$ of the escaping ion, where $V$ is the applied voltage between the specimen and the counter electrode. At the entrance of the counter electrode, the potential energy is fully converted into the kinetic energy is $1 / 2 m v^{2}$. The ion velocity, $v$, is approximately $d /$ $t(d$ : distance between specimen and detector, $t$ : time-offlight) under the assumption that the final velocity of a field evaporated ion is reached shortly after its removal from the tip surface. Then the mass-to-charge ratio $m / n$ can be derived from a simple energy balance equation

$$
\frac{m}{n}=\frac{2 e}{d^{2}}\left(V_{D C}+a V_{p}\right) t^{2}
$$

where $V_{D C}$ and $V_{P}$ are the standing and pulse voltages applied to the specimen and $\alpha$ is a pulse amplitude coupling factor to account for some loss in the effectiveness of the pulse. A three-dimensional elemental map was reconstructed from the collected data, using an inverse point projection algorithm. Under the conditions listed in Table 1, 2.4 million ions were detected. The resolution limits were about $\Delta \mathrm{x}=\Delta \mathrm{y}=0.2 \mathrm{~nm}$ and $\Delta \mathrm{z}=0.1 \mathrm{~nm}$.

\section{Results and Discussion}

\subsection{Physical properties of the ribbon.}

Fig. 2-a shows the XRD pattern obtained from the asmelt spun ribbon. A hallow pattern typical for amorphous structure was obtained. That is, formation of a crystalline structure with a long range order can be suppressed upon solidification of the alloy $\mathrm{Fe}_{75} \mathrm{C}_{11} \mathrm{Si}_{2} \mathrm{~B}_{8} \mathrm{Cr}_{4}$ at the cooling rate of the melt spinning process $\left(\sim 10^{6} \mathrm{~K} / \mathrm{s}\right)$. Fig. 2-b shows the heating trace of the ribbon $\mathrm{Fe}_{75} \mathrm{C}_{11} \mathrm{Si}_{2} \mathrm{~B}_{8} \mathrm{Cr}_{4}$ in DSC at the heating rate of $40 \mathrm{~K} / \mathrm{min}$. The crystallization event starting at the temperature $\left(T_{\mathrm{x}}\right)$ of $524 \mathrm{~K}$ was observed with the exothermic heat $(\Delta \mathrm{H})$ of $114 \mathrm{~J} / \mathrm{g}$. The ribbon was flexible so that the ribbon could be folded without crack formation. The tensile strength of the amorphous ribbon was measured as $2.1 \mathrm{GPa}$.

3.2 Spatial distribution of alloying elements within the melt spun ribbon $\mathrm{Fe}_{75} \mathrm{C}_{11} \mathrm{Si}_{2} \mathrm{~B}_{8} \mathrm{Cr}_{4}$

Fig. 3 and Fig. 4 show the results of elemental dis- 

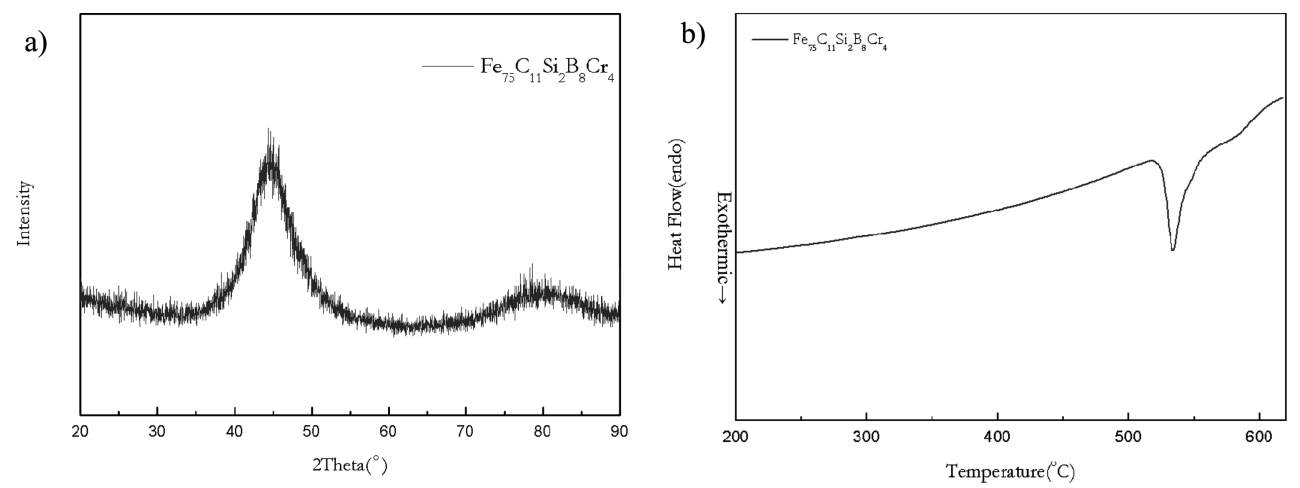

Fig. 2. Results of XRD and DSC analyses of the Fe-based ribbon.

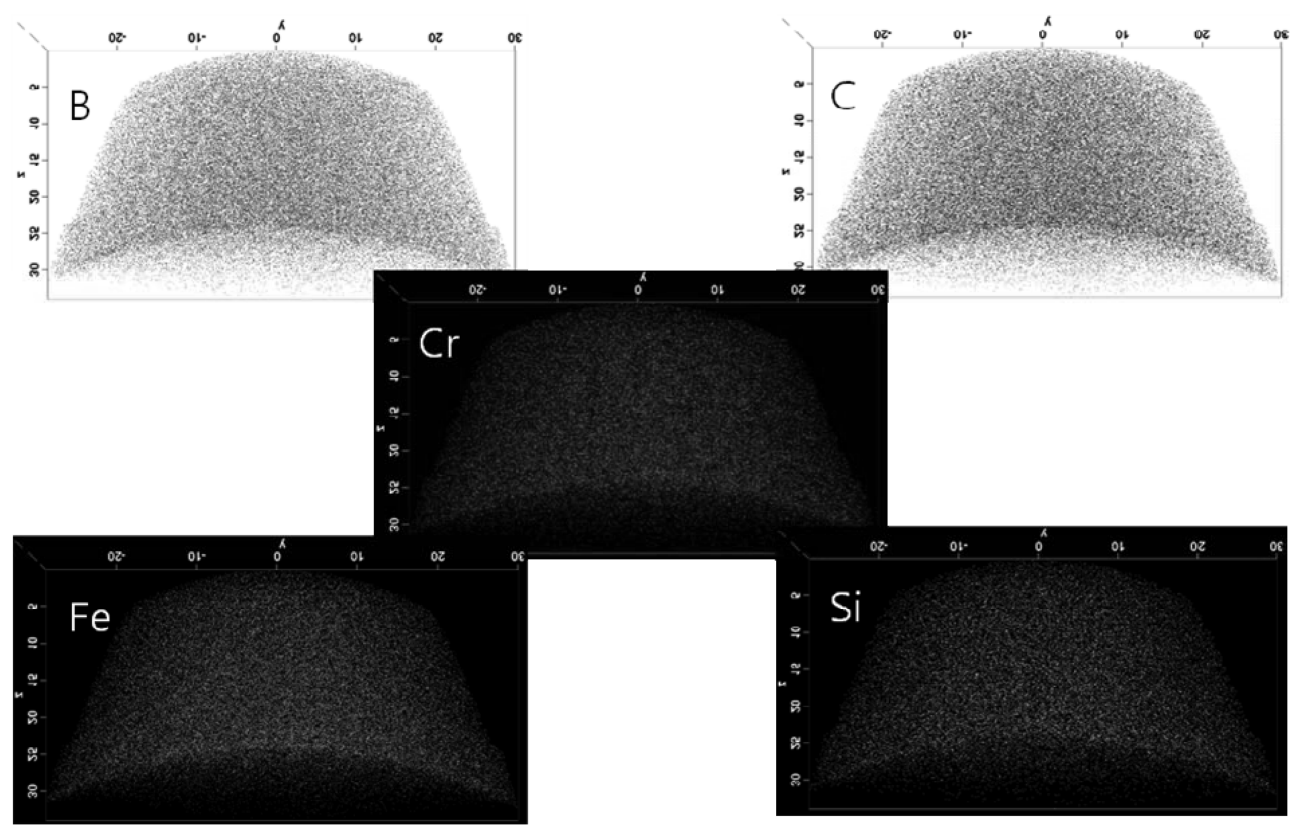

Fig. 3. Elemental distributions within the ribbon.

\begin{tabular}{|c|c|c|c|c|c|}
\hline \multicolumn{6}{|c|}{ Results } \\
\hline & Name & Reduced $x^{2}$ & $n_{d}$ & p-value & $\mu$ \\
\hline 圆 & B & 0.961 & 17 & 0.5001 & 0.0278 \\
\hline 圆 & c & 0.957 & 15 & 0.4992 & 0.0260 \\
\hline 圆 & $\mathrm{Si}$ & 0.304 & 8 & 0.9649 & 0.0107 \\
\hline 圆 & $\mathrm{Fe}$ & 1.699 & 34 & 0.0067 & 0.0521 \\
\hline 回 & $H$ & 3.382 & 5 & 0.0047 & 0.0282 \\
\hline 圆 & $\mathrm{Cr}$ & 0.847 & 11 & 0.5928 & 0.0210 \\
\hline 回 & Ga & 717.817 & 2 & $<0.0001$ & 0.2519 \\
\hline$\square$ & $\mathrm{C2}$ & 0.188 & 5 & 0.9673 & 0.0067 \\
\hline
\end{tabular}

Fig 4. Results of $\chi^{2}$-test obtained from the distribution analysis in Fig. 5.

tribution analyses taken from the APT datasets for the ribbon volume of $59 \times 59 \times 33 \mathrm{~nm}^{3}$. The elemental maps are divided into bins of 100 atoms. From each bin the elemental concentrations are determined and plotted as a concentration frequency histogram(Fig. 5). For each element, the measured distribution is compared to a binomial distribution, which represents a homogeneous elemental

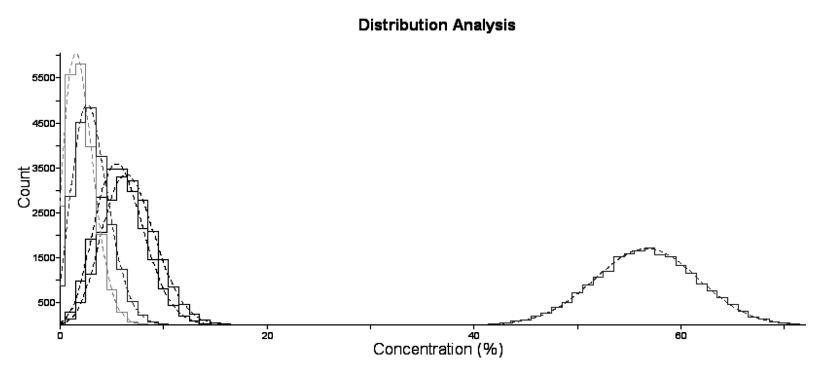

Fig. 5. Elemental distribution analyses.

distribution. The $\chi^{2}$ value gives the deviation of the measured distribution from the binomial distribution.

$$
x^{2}=\sum(N o b s-N \exp )^{2} / N \exp
$$

where $\mathrm{N}_{\mathrm{obs}}$ is the number of bins observed in the experimental data at a certain elemental concentration and 
$\mathrm{N}_{\text {exp }}$ is the number of bins that would be expected from a random alloy, as modeled by a binomial distribution. Finally, using the $\chi^{2}$ value, a critical $\chi^{2}$-value, or $p$ value, can be found. The $\mathrm{p}$ value indicates the probability that the observed distribution could have occurred by chance in a random alloy. A $p$ value of less than or equal to 0.05 is generally interpreted as justification for rejecting the null hypothesis that the observed distribution is random. Fig. 4 indicates that $\mathrm{Fe}$ is homogenously distributed. The $\chi^{2}$-values of the other solute elements are also relatively small. However, the existence of small sub-nanometer scale clusters due short range ordering cannot be completely excluded.

\section{Conclusion}

A Fe-based alloy containing high contents of carbon and strong carbide forming elements could be prepared as an amorphous ribbon through a melt spinning process. The amorphous ribbon was very flexible and exhibited a crystallization event starting at $524 \mathrm{~K}$ during the continuous heating(heating rate: $40 \mathrm{~K} / \mathrm{min}$.) in a DSC. From the results of atom probe analyses of the Fe-based amorphous ribbon, homogeneous distributions of alloying elements within the amorphous ribbon can be concluded. That is, any nano-scale segregation zone of carbide forming elements was not detected within the high carbon Febased amorphous alloy.

\section{Acknowledgement}

This work was supported by the National Research Foundation of Korea Grant funded by the Korean Government (NRF-2011-013-D00052).

\section{References}

1. J. J. Becker, J. Appl. Phys., 52, 1905 (1981).

2. H. Matsumoto, A. Urata, Y. Yamada and A. Inoue, IEEE Trans. Magnetics, 46, 373 (2010).

3. K. Hono, D. H. Ping, M. Ohnuma and H. Onodera, Acta Materialia 47, 997 (1999).

4. K. B. Kim, X. F. Zhang, S. Yi, M. H. Lee, J. Das and J. Eckert, Philos. Mag. Lett., 88, 75 (2008).

5. C. C. Hays, C. P. Kim and W. L. Johnson, Appl. Phys. Lett., 75(8), 1089 (1999).

6. E. S. Park and D. H. Kim, Intermetallics, 18, 1867 (2010).

7. A. A. Kuendig, M. Ohnuma, T. Ohkubo and K. Hono, Acta Mater., 53, 2091 (2005).

8. X. Wang, Q. P. Cao, Y. M. Chen, K. Hono, C. Zhong, Q. K. Jiang, X. P. Nie, L. Y. Chen, X. D. Wang and J. Z. Jiang, Acta Mater., 59, 1037 (2010).

9. D. Prabhu, R. Veerababu, R. Balamuralikrishnan, A. Narayanasamy and K. Chattopadhyay, Mater. Sci. Eng. B, 177, 791 (2012).

10. H. Li, Z. Lu and S. Yi, Met. Mater. Int., 15, 7 (2009).

11. M. K. Miller and R. G. Forbes, Mater. Charact., 60, 461 (2009). 